\title{
Path Selection of Recognizable Technology for Unlawful Interference in Cabins*
}

\author{
Xiaoyong Yang \\ College of Civil Aviation Safety Engineering \\ Civil Aviation Flight University of China \\ Guanghan, China
}

\begin{abstract}
This paper discussed the characteristics and development trends of the recognizable techniques of in-flight unlawful interference behavior based on multidisciplinary background. The author analyzed the theoretical and practical exploration in aviation security before and after 9/11 from the aspects of aviation security law, criminal profiling, attribution of hijacking and explosive behaviors, terrorists' information profiling, and behavioral pattern recognition. This paper summarized the merits and demerits of different methods, and established the basis for further researches in recognizing the unlawful interference in cabin.
\end{abstract}

Keywords-unlawful interference; recognition; formation of behavior; criminal psychology

\section{INTRODUCTION}

As the most dangerous type of behavior in aviation crime, the risk of unlawful interference in civil aviation is far more dangerous than that of other disturbing behaviors. The analysis of unlawful interference in cabin is always the key research field of aviation security theory, and attracts attention of many scholars. In the past, from the standpoint of international law and aviation criminal justice, a lot of researches on the three major conventions and other relevant international criminal law norms have emerged. However, these researches mainly focused on the static description and afterwards penalties discussion for the unlawful interference in the cabin, rarely concerning the further dynamic analysis on unlawful interference behavior itself. Aviation security research has clearly realized that the "laws and regulations makers should make efforts in preventing the unlawful interference behaviors. But they should be very careful to guarantee that the measures required by the regulations should be practical and usable to the executors".[1] Comparing to the clarification of legal nature and judicial responsibility of various types of unlawful interference in cabin, the aviation security personnel who has been engaged in the long-term work care more about: the psychological and physiological mechanism of various illegal behaviors, the relationship between the mood swings of the offender with behavior characterization, as well as the accurate judgment of all kinds of behavior and the proper control. The demand in this area could not be purely satisfied by law,

*Source of subject: CAAC Security Capability Construction Project "Comprehensive Application and Capability Construction of International Civil Aviation Security Information"; CAFUC Project "Aviation Crime and Passenger Security Management in International Civil Aviation History". instead, it needs interdisciplinary efforts of criminal psychology and social psychology.

\section{CHARACTER RECOGNITION OF OFFENDERS ON THE BASIS OF PSYCHOLOGICAL PORTRAITS}

The one that entered into the criminal behavior identification field is the efforts of psychologists in the field offender profiling, which has lots of other similar names in the English language, like the criminal profiling, criminal personality profiling, criminological profiling, behavioral profiling or criminal investigative analysis etc. Though the connotations of these concepts are slightly different, in Chinese, they are unified translated as crime psychological portrait or psychological profiling technology.[2] The research path is trying to understand and repeat the behavior patterns of offenders, answer the question why some certain people implement certain types of crime, analyze which type of behavior of the offenders could reflect their background and personality.[3] Though the early achievements of this aspect are not rich, the impact is very big: it directly makes the FBI establish the Behavior Science Unit (BSU) and the National Center for Analysis of Violent Crime (NCAVC) to perform the offender profiling specially.

However, the research path of performing psychological or geographical portrait to the offender has always been criticized by the academic community for its methodological flaws. In addition, the biggest problem of using this method in the field of aviation security is: the study of the crime patterns is always the deduction and analysis after the happening of the case, not suitable for advance forecast or on-the-spot judgment in the midst of the event. Even so, the attention of the offender portrait personnel on the main factors influencing the crime, including individual factors and environmental factors, can still be deemed as a reference model to understand aviation crime.

\section{IDENTIFICATION OF THE BEHAVIOR MOTIVATION OF THE HIJACK}

The attempt to analyze the behavior of unlawful interference from the perspective of the psychological motivation or personality defect will surely lead the researchers to step onto the way of behavior classification, namely to attempt to classify a certain aviation offender into a pre-set class or type. Domestic researchers in prophase study 
has once classified over 90 unlawful interference offenders into six crime categories according to the hijack case data of China civil aviation in the past 30 years, including terrorist type of hijack, escaping legal punishment type, pursuit of material comforts, emotional crisis, relationship attack, and mental disorder type.[4] This type of recognition based on crime motivation completely covers all types of hijack events happened in our country. However, during the specific classifying process, the researchers found that a lot of motivation behind the behavior of illegal interference model is vague, even cross with each other.[5] Since the occurrence of any crime is the result of complicated interaction of a few individual factors or factors between the environment and the internal, the attempt to determine the only cause while explaining the crimes is inaccurate for it may neglect multiple factor functioned during the behavior process. And right because of this, we encounter huge block in the process of hoping to apply the existing classification criterion to identify the unlawful behavior in cabin, which also urges us to look for a more reasonable and effective solution on this basis.

In fact, if the identification process of criminal behavior motivation is further simplified, its adaptation scope may continue to expand. Only taking the hijacked aircraft behavior for instance, in the process of its implementation, the hijacked aircraft often is reflected in state that relevant personnel is kidnapped, and as a result, the mechanism of this kind of behavior is similar to the crime of taking hostages. Early hostage research experts found that in some hijacking cases, the motives and demands of the hijackers were sometimes clear and sometimes rather vague. For example, some hijackers asked the pilot to fly the plane from one country or place to another country or place. Some of the hijackers required the government to agree to release their accompanies; Some hijackers demanded for huge ransoms; and Some hijackers did not have a clear political or economic appeal, merely requiring the pilot to fly the plane from one place to another without any additional requirements after landing. How to explain these different behaviors? In their early studies, criminologists Miron and Goldstein explained the main motivations for hostage-taking criminals by using the two terms of instrumental hostage-taking and expressive hostagetaking.[6] They believed that in the act of instrumental hostage-taking, the target of a criminal is clear, such as pursuing for material interests. In a series of hijacked planes in the 1990s, almost all of the hijackers' destinations were in Taiwan or Hong Kong. Though most of the hijackers claimed for political defection, it was found in the process of investigation later that the real reason attracting them was the huge economic development difference between the mainland China and the two major destinations. Therefore, the pursuing of material and economic interests were the main motivations of such offenders. The purpose of the expressive hostagetaking is psychological purpose: the offender wants to be the target of attention, and can control his own destiny. Such expressive hostage-taking offenders often feel lack of control of their own life, and they hope themselves to become important, and believe that the media report about their hijacking or kidnapping act could help them accomplish this goal. In the act of Jiang Min hijacking the plane of Xiamen Airline of China[7], the offender wanted to get rid of the feeling of marriage failure through hijacking and thus became a person attracting attention of others. Miron and Goldstein, however, also found that sometimes the hostage-taking offender was instrumental behavior at first, but when finding that their request was unrealistic or cannot be met, then evolved into the expressive hostage-taking. This shows that when the motivation attribution is analyzed for the criminal, it is necessary to pay attention to the possibility of motivation change. In conclusion, the focus of research on the motivation identification of such crimes has gradually shifted from the static psychological characteristics of the criminal to the dynamic behavior pattern.

\section{TERRORIST IDENTITY INFORMATION SCREENING}

These previous offender recognition technologies are qualified for post-mortem analysis for conventional criminal individual and behavior, but are hard to exert power when facing to the unpredictable well-planned terrorist. Then how to predict the possible aviation security threat, accurately judge its sources, fragile attribute, and damage characteristics[8] of threats, and screen out the most risky "unconventional behavior" in early stage, has become a difficult problem that the practice field needs to solve urgently. When the method of recognizing the unlawful interference behavior from the internal of the psychological behavior is blocked, another external recognition model is right under exploration, which hopes to become capable in aware of such individual having prearranged damage plan similar to terrorists, and hopes to provide a simple and effective way to identify them. At first, the on-the-spot unlawful interference behavior recognition technology for the civil aviation field was realized by the method of racial profiling. But this recognition method, which involves passengers' gender, race, color, religion or ancestry, was quickly challenged by the "racial discrimination" of public opinion. And then, Israel introduced in the famous psychologist Paul Ekman's research findings of human emotional characteristics, and developed its own set of passenger screening technology. Although this technology is still criticized by the public due to its concerned ethical disputes, it exerts its function to a large extent, and satisfied part of official expectations.

At the time when the Israel behavior recognition technology was being implemented and promoted, the civil aviation department of the United States was also actively improving the recognition technology of passenger suspicious behavior in accordance with its special conditions. In the initial stage, the US government focused on the method of screening suspicious passengers by the blacklist way, the Department of Homeland Security (DHS) had developed a series of passenger prescreening and "terrorism blacklist" systems based on the automatic selectee. In this system, DHS used the terrorist screening database of the FBI to verify passengers, airlines staff, the airport staff and any other personnel who attempts to enter the controlled area, including their names and the related license certification information, thus to recognize the known terrorists or other suspicious personnel worldwide. From days before 9-11 event to now, the transportation security administration (TSA) of the United States has gradually developed multiple identity information screening methods, 
including the "no-fly list", observation list of selectee, computer aided passenger screening system (CAPS), the first generation Computer-Assisted Passenger Pre-screening System (CAPPS I), and the second generation ComputerAssisted Passenger Pre-screening system (CAPPS II) [9], and Secure Flight[10]. This series of efforts for strengthening aviation security mostly rely on the known terrorist threats information database or intelligence information, and intelligence information provided by the security department, which lack of dynamic monitoring ability for suspicious behavior and personnel on the security field. At the same time, the biggest challenge which also directly results in the abolishing of CAPPS II is: the pre-collected information exposes citizen private information, and is conflicted to the related provisions of the constitution of the United States. As a result, in the security flight plan implemented after 2005, TSA began to consider shifting the focus from simple comparison of passenger identity information to recognition and screening of dynamic behavior at security sites

\section{MORPHOLOGICAL RECOGNITION OF SUSPICIOUS BEHAVIOR}

Due to the failures of identity screening method in the actual promotion process, TSA has gradually promoted the Screening Passengers by Observation Technique since 2003, and has set up special behavior recognition officer (BDO) in pilot airports, which shall be responsible for recognizing and screening any suspicious behavior occurs at the security inspection site. The BDO who has accepted special training is able to recognize the behavior characteristics of the suspicious personnel based on some certain behavior baselines, like the high level stress, anxiety and deception behavior characteristics, and thus further do the special screening to the personnel. The BDO adopts non-contact behavior observation, analysis and detection measures to screen passengers and find out the unconscious behavior made due to the fear of being seen through. Based on the research of behavioral scientists, this method find that those who intentionally hide their real behavior, often lack of normal behavior or has abnormal behavior in facial expression, dress or behavior. TSA believes that these two hypotheses are applicable for most of the situations, which avoid the ethnical criticism like "discrimination" and "racial bias" faced by passenger identity screening. SPOT project has been developed so fast that, by May 2010, there were 3, 000 people employed at 161 airports as BDO, and their salaries are \$212 million a year.

Certainly, this method is not universally applicable. Due to its subjective attribute, it often results in passengers' blame and complain to the civil aviation department. In May 2010, GAO of the United States made the fierce criticism to the SPOT project of the TSA.[11] It believes that the method lacks of strict scientific verification, and the effect in anti-terrorism is far less than its huge expenditure. And moreover, up to now, it hasn't succeeded in recognition of any terrorist. Because of this, the American media ironically calls the BDO of the SPOT the "wizard wearing masks plays tricks in front of passengers". In response to the huge pressure of public opinion, DHS pointed out in its independent survey report released in April 2011 that the morphological recognition technology is indispensable in finding out a suicide bomber attack and suspicious illegal behavior, especially comparing with the random passenger screening, it is nine times higher in the effectiveness of recognizing high risk passengers.[12] Since the term for SPOT project implementation is not long, it has no sufficient successful cases to respond to the public doubt. But the practice of Israel passenger screening technology and the attitude of greatly promoting the morphological recognition technology in the new edition of Attachment-17 which was formally implemented in July 2011, making us unable to neglect the huge development potential of relative technologies based on suspicious behavior analysis.

\section{CONCLUSION}

At present, there are different thoughts on the research of the field recognition technology and measures for the unlawful cabin interference. And each path has both its own methodology which is different from others and similar objective-guide. In short term, it is impossible that any certain research path could suppress others. But in general, early warning, dynamic analysis and real-time monitoring targeting for the characteristics of the field behaviors would become the indispensable demand for the recognition and disposal of unlawful cabin interference in the future. No matter under what kind of aviation security system or air defense security situation, it will take the practical, convenient, effective and non-interference performances as its development direction.

\section{REFERENCES}

[1] C. Williams, S. Waltrip. Aircrew Security: A Practical Guide. New York: Routledge. 2004

[2] B. E. Turvey, Criminal Profiling: An Introduction to Behavioral Evidence Analysis, 4th ed. New York: Academics, 2011.

[3] P. B. Ainsworth. Offender profiling and crime analysis. Cullompton: Willan, 2001.

[4] Yuanhua He. Aviation Security Principle [M]. Beijing: China Civil Aviation Publishing House, 2009

[5] Xiaoyong Yang. Study on Classification of Civil Aviation Security Events [J]. Journal of Civil Aviation Flight University of China, 2008 (6) $: 8-12$

[6] M. S. Miron, A. P. Goldstein. Hostage. New York: Pergamon, 1979

[7] Shengli Song. Collection and Analysis on China Civil Aviation Hijack Events [G]. Beijing: compiled and printed by Public Security Bureau of CAAC, Civil Aviation Flight University of China, 2008.

[8] Xiaoyong Yang. Risk Evaluation Method in Decision-making of Public Security Management ---- View Angle of Aviation Security Management [J]. Social Science Research, 2013 (3): 117-119.

[9] USGA Office . Aviation Security: Computer-Assisted Passenger Prescreening System Faces Significant Implementation Challenges, GAO-04-385. Washington: United States Government Accountability Office. 2004.

[10] C. A. Berrick. Aviation Security: DHS Has Made Progress in Securing the Commercial Aviation System, but Key Challenges Remain, GAO08-139T . Washington: United States Government Accountability Office. 2007.

[11] USGA Office. Aviation Security: Efforts to Validate TSAs Passenger Screening Behavior Detection Program Underway, but Opportunities Exist to Strengthen Validation and Address Operational Challenges (GAO-10-763). Washington: United States Government Accountability Office. 2010. 
[12] L. Wills. U.S. House of Representatives Committee on Science and Technology Subcommittee on Investigations and Oversight Testimony. Washington: Department of Homeland Security. 2011. 